\title{
PROPORTIONS OF MAXILLARY ANTERIOR TEETH RELATIVE TO EACH OTHER AND TO GOLDEN STANDARD IN CHITWAN MEDICAL COLLEGE
}

Meena Kumari Mishra, ${ }^{1 *}$ Manjeev Guragain, ${ }^{1}$ Smriti Narayan Thakur, ${ }^{1}$ Sanjeeb Chaudhary ${ }^{2}$

${ }^{1}$ Department of Prosthodontics and maxillofacial prosthetics, School of Dental Science, Chitwan Medical College, Bharatpur, Chitwan, Nepal. ${ }^{2}$ Department of Conservative dentistry, School of Dental Science, Chitwan Medical College, Bharatpur, Chitwan, Nepal.

*Correspondence to: Dr. Meena Kumari Mishra, Department of Prosthodontics and maxillofacial prosthetics, School of Dental Science, Chitwan Medical College, Bharatpur, Chitwan, Nepal. Email: drmeenamishra400@gmail.com

\begin{abstract}
Introduction: One of the most important aspects of aesthetic dentistry while restoring or replacing maxillary anterior teeth is the creation of harmonious proportion between the widths of them. The appearance of anterior teeth is critical for an attractive face and pleasing smile. The dimensional determination of maxillary anterior teeth is an important factor for both, esthetic and function. Materials and Methods: This study was conducted in $\mathbf{1 4 0}$ dentate subjects. Out of the 140 subjects, $70(50 \%)$ were males and $70(50 \%)$ were females. The age of the patients in this study ranged from 18 to 50 years. Maxillary impressions of selected subjects were made with an irreversible hydrocolloid impression material. The mesiodistal width of the maxillary anterior teeth was measured from the casts with a Boley gauge.

Results: The mean width ratios were 0.83 for right $\mathrm{LI} / \mathrm{Cl}$ and 0.85 for left $\mathrm{LI} / \mathrm{Cl}, 1.12$ for right $\mathrm{CN} / \mathrm{LI}$ and 1.1 for left $\mathrm{CN} / \mathrm{LI}$ in total population. The mean width ratios in male group were 0.83 for right $\mathrm{LI} / \mathrm{Cl}$ and 0.87 for left $\mathrm{LI} / \mathrm{Cl}, 1.14$ for right $\mathrm{CN} /$ $\mathrm{LI}$ and 1.1 for left CN/LI. Similarly, in female group the mean width ratios were 0.82 for right $\mathrm{LI} / \mathrm{Cl}$ and 0.83 for left $\mathrm{LI} / \mathrm{Cl}$, 1.1 for right $\mathrm{CN} / \mathrm{LI}$ and 1.1 for left $\mathrm{CN} / \mathrm{LI}$. Conclusion: In the evaluation of $\mathrm{LI} / \mathrm{Cl}, \mathrm{CN} / \mathrm{LI}$, WLRs golden proportion was not found in left and right for both sexes.
\end{abstract}

Key words: Anterior teeth, Esthetics, Golden proportion

\section{INTRODUCTION}

Dental esthetics is a science based on the general taste of society ${ }^{1}$. One of the most important aspects of aesthetic dentistry while restoring or replacing maxillary anterior teeth is the creation of harmonious proportion between the width of them. ${ }^{2}$ The appearance of anterior teeth is critical for an attractive face and pleasing smile ${ }^{3}$. According to Young" it is apparent that beauty, harmony, naturalness and individuality are major qualities" of esthetics. The dimensional determination of maxillary anterior teeth is an important factor for both, esthetic and function. Lombardi ${ }^{5}$ proposed that dental and facial aesthetics are optimized if central incisor-to-canine width is repeated in proportion when patient is viewed from the front. This proportion was called golden proportion and is approximately 1.618 to 1 . He stated the golden proportion was too strong for use in dentistry. Preston $^{6}$ found only $17 \%$ of the samples studied actually had golden proportion between the perceived width of the maxillary central and lateral incisors.

White ${ }^{7}$ projected the concept of "Correspondence and Harmony." The basis of this concept was that the temperaments called for a characteristic association of tooth form and color, and that harmony called for a corresponding proportion and size of tooth to that of the face, and a tooth color in harmony with facial complexion; that both form and color were modified to be in harmony with sex and age. White considered the detailed line values of the teeth singly, and in the over-all composition, and thought that these were modified by age and sex. Levin ${ }^{8}$ described a system of esthetic prediction that has been used since antiquity. The naturality of the golden proportion system was emphasized by showing examples from nature and how artists and designers used it.

The relationship between the length and width of the central incisor is another important concept of 
esthetics. The average maxillary central incisor has a length to width ratio of 10:9.1 The recommended proportion in dental anatomy and for dental laboratory technicians is 10.5:8.5.9,10 However, there is little scientific data in the dental literature to use as a guide for defining the proper size and shape of anterior teeth or determining normal relationships for them ${ }^{11}$. So the aim of this study was to find out the proportions of Maxillary Anterior Teeth relative to each other and objective was to evaluate the occurrence of golden proportion in the anterior teeth and to assess the width to length proportion of maxillary central incisors.

\section{MATERIALS AND METHODS}

This hospital-based prospective observational study was conducted in 140 dentate subjects in the Department of Prosthodontics and Maxillofacial prosthetics, College of Dental Science, Chitwan Medical College, Bharatpur, Nepal. Out of the 140 subjects, 70 (50\%) were males and $70(50 \%)$ were females. The age of the patients in this study ranged from 18 to 50 years. Most of the patients, 90\% were in the age group 20-30 years followed by patients in the age group of $\leq 20$ years.

Inclusion criteria were $\geq 18$ years old; born in Nepal; with an Angle Class I molar relationship, pleasing profile, and intact morphologically normal permanent dentition up to the second molar. Subjects with a history of orthodontic treatment; a Class II or Class III molar relationship; gingival inflammation and hypertrophy in the upper anterior region; severe attrition; crowns or proximal restorations placed in the anterior teeth; and a history of congenital anomaly, orbital disease, trauma, or facial surgery were excluded.

Approval for the study was obtained from Chitwan Medical College Institutional Review Committee (CMC-IRC). Verbal consent was taken from the subjects. The subjects were comfortably seated on a dental chair in a relaxed state in an upright position with the head resting firmly against the headrest. Maxillary impressions of selected subjects were made with an irreversible hydrocolloid impression material tray (Zelgan ${ }^{\circledR} 2002$ Dustfree Alginate Impression Material, DENTSPLY DeTrey $\mathrm{GmbH}$, Konstanz, Germany) and poured into a Type III dental stone (Kalstone, Kalabhai Karson Pvtd Ltd, Mumbai, India). The mesiodistal width of the maxillary anterior teeth was measured from the casts with a Boley gauge (Taurus 811-2, SS Medident Instruments [Pvt] Ltd, Sialkot, Pakistan) as shown in Figure 1.

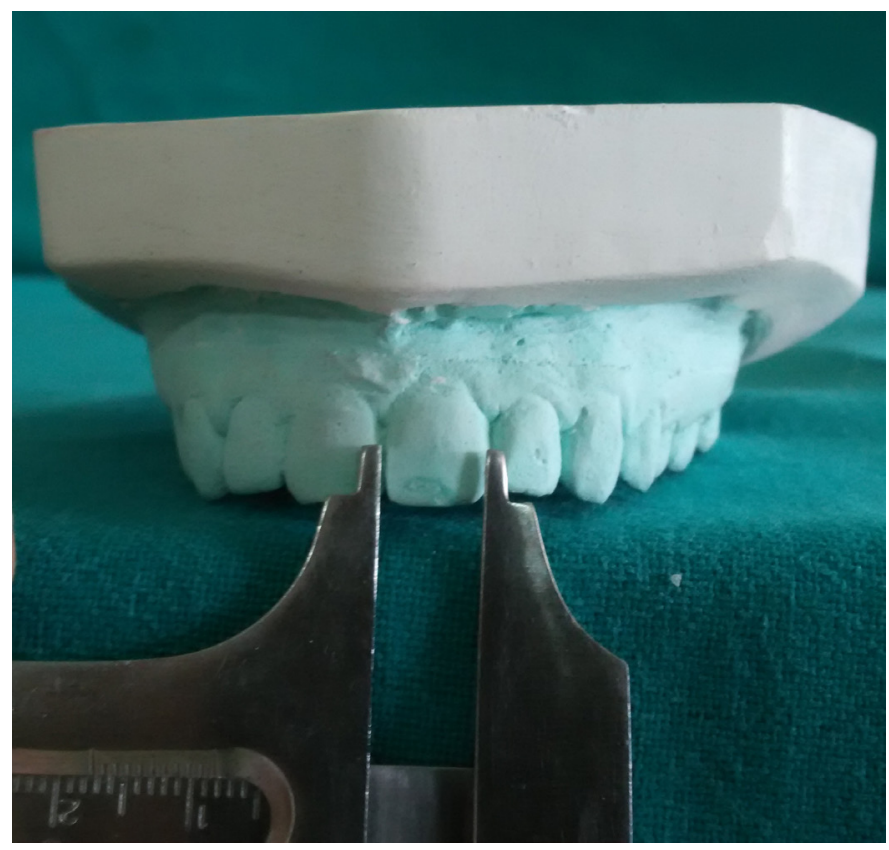

Fig:1 Measurement of mesiodistal width of central incisor.

\section{STATISTICAL METHODS}

Collected data were entered into Microsoft ${ }^{\circledR}$ Excel 2007 software. Descriptive statistics were calculated (mean and standard deviation) and also tabular presentation was done. For inferential statistics. Data were analyzed using GraphPad software (San Diego California USA). P-value was calculated using one sample t-test.

\section{RESULTS}

The data collected from the 140 subjects 70 males and 70 females were analyzed to find out proportions in the maxillary anterior teeth relative to golden proportion. According to the results of one sample t-test, ratio for maxillary $\mathrm{LI} / \mathrm{Cl}$ and $\mathrm{CN} / \mathrm{LI}$ are shown in table 1 . The mean width ratios were 0.83 for right $\mathrm{LI} / \mathrm{Cl}$ and 0.85 for left $\mathrm{LI} / \mathrm{Cl}, 1.12$ for right $\mathrm{CN} / \mathrm{LI}$ and 1.1 for left $\mathrm{CN} / \mathrm{LI}$ in total population. The mean width ratios in male group were 0.83 for right $\mathrm{LI} / \mathrm{Cl}$ and 0.87 for left $\mathrm{LI} / \mathrm{Cl}, 1.14$ for right $\mathrm{CN} / \mathrm{LI}$ and 1.1 for left CN/LI. Similarly in female group the mean width ratios were 0.82 for right $\mathrm{LI} / \mathrm{Cl}$ and 0.83 for left $\mathrm{LI} / \mathrm{Cl}, 1.1$ for right $\mathrm{CN} / \mathrm{LI}$ and 1.1 for left CN/LI. There was a stastically significant difference between the 
proportion of the right lateral incisor width based on golden proportion $(p<0.001)$. For the left side of the jaw, the difference was also significant $(p<0.001)$. Therefore, considering the width of the upper teeth, no golden proportion existed. Table 2 shows WLRs of maxillary central incisors in total population, male and female on both right and left side. The mean WLRs in right $\mathrm{Cl}$ were found to be 0.84 in total population, 0.8 in male and 0.9 in female. The mean WLRs in left $\mathrm{Cl}$ were found to be 0.83 in total population, 0.8 in male and 0.72 in female.

Table-1: Proportion of maxillary anterior teeth width relative to each other.

\begin{tabular}{|l|l|l|l|l|l|l|l|l|l|l|}
\hline \multirow{2}{*}{ Teeth proportions } & \multicolumn{4}{c|}{ Total } & \multicolumn{3}{c|}{ Male } & \multicolumn{3}{c|}{ Female } \\
\cline { 2 - 10 } & Mean & SD & P value & Mean & SD & P value & Mean & SD & P value \\
\hline $\begin{array}{l}\text { Width of right lateral inci- } \\
\text { sor to width of right central } \\
\text { incisor }\end{array}$ & 0.83 & 0.087 & 0.0001 & 0.83 & 0.099 & 0.0001 & 0.82 & 0.072 & 0.0001 \\
\hline $\begin{array}{l}\text { Width of right canine to } \\
\text { width of right lateral inci- } \\
\text { sor }\end{array}$ & 1.12 & 0.124 & 0.0001 & 1.14 & 0.125 & 0.0001 & 1.1 & 0.119 & 0.0001 \\
\hline $\begin{array}{l}\text { Width of left lateral inci- } \\
\text { sor to width of left central } \\
\text { incisor }\end{array}$ & 0.85 & 0.096 & 0.0001 & 0.87 & 0.105 & 0.0001 & 0.83 & 0.082 & 0.0001 \\
\hline $\begin{array}{l}\text { Width of left canine to } \\
\text { width of left lateral incisor }\end{array}$ & 1.1 & 0.13 & 0.0001 & 1.1 & 0.13 & 0.0001 & 1.1 & 0.132 & 0.0001 \\
\hline
\end{tabular}

Correlation analysis was performed using GraphPad software (San Diego California USA). P-value was calculated using one sample $t$-test.

Table 2. Width-to-length ratio of maxillary central incisors.

\begin{tabular}{|l|l|c|l|l|l|l|l|l|l|l|}
\hline \multirow{2}{*}{ Tooth } & \multicolumn{3}{|c|}{ Total } & \multicolumn{3}{c|}{ male } & \multicolumn{3}{c|}{ female } \\
\cline { 2 - 10 } & Mean & SD & P value & Mean & SD & P value & Mean & SD & P value \\
\hline $\begin{array}{l}\text { WLRs of Right central inci- } \\
\text { sor }\end{array}$ & 0.84 & 0.128 & 0.0001 & 0.8 & 0.136 & 0.0001 & 0.88 & 0.101 & 0.0001 \\
\hline $\begin{array}{l}\text { WLRs of Left central inci- } \\
\text { sor }\end{array}$ & 0.83 & 0.113 & 0.0001 & 0.79 & 0.122 & 0.0001 & 0.72 & 0.082 & 0.0001 \\
\hline
\end{tabular}

Correlation analysis was performed using GraphPad software (San Diego California USA). P-value was calculated using one sample $t$-test.

\section{DISCUSSION}

Mathematical or geometrical relation between anterior teeth is important to achieve an esthetic result. It would be helpful if statistically reliable results existed to support existing theories12. Lombardi5 stated the golden proportion was too strong for use in dentistry. Several studies were conducted to find application of golden proportion in dentistry. However, the golden proportion idea can no longer be considered since many articles found that golden proportion didn't exist.

Ward in 2001 recommended using other ratios, such as 0.70 rather than 0.618 to provide more pleasing appearance.13 The current study found width ratio of 0.83 for right $\mathrm{LI} / \mathrm{Cl}$ and 0.85 for left $\mathrm{LI} / \mathrm{Cl}, 1.12$ for right $\mathrm{CN} / \mathrm{LI}$ and 1.1 for left CN/LI in total population. Hasanreisoglu et al. viewed 100 Turkish dental students and does not found the existence of the golden proportion for the maxillary anterior teeth.11 Marzok13 studied in 49 Malaysian population (22 Chinese, 14 Indians and 13 Malay) and found LI/Cl -0.738 in Chinese, 0.710 in Indian and 0.744 in Malay and CN/LI- 0.748 in Chinese, 0.801 in Indian and 0.786 in Malay. Parnia14 
studied in 100 Tabriz dental students and found LI/ $\mathrm{Cl}-0.66$ on right side, 0.63 on left side and CN/ LI0.66 on right side and 0.68 on left. Rokaya15 et al studied in 150 Nepalese subjects and found $\mathrm{LI} / \mathrm{Cl}$ was $66 \%$ and $\mathrm{CN} / \mathrm{LI}$ was $70 \%$.

The current study found poor correlation between teeth dimensions and the golden proportion which is similar to the findings of other studies.11,13-15 Several studies were conducted to find application of golden proportion in dentistry. However, the golden proportion idea can no longer be considered since many articles found that golden proportion didn't exist.

The crown width to height ratio has been accepted as the most stable reference by authors.11 Peixoto et al. reported that the ideal WLRs for the central incisor should lay between 75 and $80 \%$. However, the ratio which allows an aesthetically acceptable appearance is in the 65 to $85 \%$ range 16 Petricevic et al. studied the WLRs of maxillary anterior teeth in a Croatian population and found that WLRs for central incisors was $90 \%$. Rokaya15 et al. studied in 150 Nepalese subjects were divided in three facial types; broad, average and narrow group. The WLRs for $\mathrm{Cl}$ in the total population were $90 \%$ and results showed no significant difference among three facial types. The results of our study showed WLRs lower than that of study by Rokaya, $83 \%$ in right side and $84 \%$ in left side. Parnia14 studied in 100 Trabiz dental student and found WLRs, $83 \%$ in right side and $82 \%$ in left side and Marzok13 in 49 Malaysian population ( 22 Chinese, 14 Indians and 13 Malay) and found WLRs- $85 \%$ in Chinese, $87 \%$ in Indian and $86 \%$ in Malay which is similar to our study.

Oh17 studied in 93 adult Korean and found the average W/LRs of maxillary central incisors is the greatest in patients over sixty years of age. In patients aged forty to fifty years old, the maxillary central incisor WLRs of males is higher than that of females, similar to our study.

\section{LIMITATIONS}

This study has several limitations. The accuracy in determining the dimensions of teeth was compromised in two stages- one during impression making and the other during cast making. This could have been avoided if the teeth were measured intraorally but the patients' comfort would have been compromised.

\section{CONCLUSION}

- In the evaluation of $\mathrm{LI} / \mathrm{Cl}, \mathrm{CN} / \mathrm{LI}, \mathrm{WLRs}$ golden proportion was not found in left and right for both sexes.

\section{REFERENCES}

1. Arthur S Brisman. Esthetics: a comparison of dentist' and patient' concepts. JADA 1980;100;345-352.

2. Nandini T. Niranjan, Aruna Kanaparthy, Rosaiah Kanaparthy, Kiran H. Photographic and manual evaluation of golden percentage and recurrent aesthetic dental proportion in aesthetic smiles. J Evolution Med Dent 2016;38(5):2267-70.

3. Tripathi S, Aeran H, Yadav S, Singh S., Singh R, Poran C. Canine Tip Marker : A Simplified Tool for Measuring Intercanine Distance. J Prosthodont 2011;20:391-396.

4. YOUNG HA. Selecting the anterior tooth mold. J Prosthet Dent 1954;4:748-760.

5. Lombardi RE. The principles of visiual perception and clinical application to denture esthetics. J Prosthet Dent 1973; 29: 358-82

6. Preston JD. The golden proportion Revisted. J Esthet Dent 1993;5:247-251.

7. Waliszewski M. Restoring dentate appearance : a literature review for modern complete denture esthetics. J Prosthet Dent 2005;93(4):386-394.

8. Mahshid M, Khoshvaghti A, Varshosaz M, Vallaei N. Evaluation of golden proportion in individuals with an esthetic smile. J Esthet Restor Dent 2004;16(3):185-93.

9. Academy of Denture Prosthetics. Principles, concepts, and practices in prosthodontics-1976. J Prosthet Dent 1977;37(2):204-21.

10. Arrangement and articulation of Trubyte teeth:asymmetry and its influence on tooth arrangement. York, Pa, Dentsply International Inc.., 1976, p11. 
11. Hasanreisoglu Ufuk, Semih Berksun, Kerem Aras Al. An analysis of maxillary anterior teeth: Facial and dental proportions. J Prosthet Dent 2005;:530-38.

12. Fayyad MA, Jamani KD, Aqrabawi J: Geometric and mathematical proportions and their relations to maxillary anterior teeth. JCDP 2006, 7 (5): 6270.

13. Peixoto LM, Louro RL, Gomes AA, de Nascimento APC: Photographic analysis of esthetic dental proportions. Rev GauchaOdontol 2012, 60 (1): 13-17

14. Rokaya D, Kitisubkanchana J, Wonglamsam A, Santiwong P, Srithavaj T, Humagain M. Maxillary Anterior Teeth Proportion in a Nepalese
Population. Kathmandu Univ Med J (KUMJ) 2015;13(51):244-9.

15. Parnia F, Hafezeqoran A, Mahboub F, Moslehifard E, Koodaryan R, Moteyagheni R, Saber FS: Proportions of maxillary anterior teeth relative to each other and to the golden standard in Tabriz dental faculty students. JODDD 2010;4(3): 83-86.

16. Al-Marzok MI, Majeed KRA, Ibrahim IK. Evaluation of maxillary anterior teeth and their relation to the golden proportion in Malaysian population. BMC Oral Health 2013;13:9.

17. Oh YA, Yang HS, Park SW, Lim HP, Yun KD, Park C. Analysis of the width ratio and wear rate of maxillary anterior teeth in the Korean population. J Adv Prosthodont 2017 Apr;9(2):93-98. 